\title{
Prepulse inhibition in patients with bipolar disorder: a systematic review and meta-analysis
}

\author{
Zhen Mao ${ }^{1,2}$, Qijing Bo ${ }^{1,2^{*}}$ (D) Weidi Li ${ }^{1,2}$, Zhimin Wang ${ }^{1,2}$, Xin Ma ${ }^{1,2}$ and Chuanyue Wang ${ }^{1,2}$
}

\begin{abstract}
Background: Prepulse inhibition (PPI) is a measurement method for the sensory gating process, which helps the brain adapt to complex environments. PPI may be reduced in patients with bipolar disorder (BD). This study investigated PPI deficits in BD and pooled the effect size of PPI in patients with BD.

Methods: We conducted a literature search on PPI in patients with BD from inception to July 27, 2019 in PubMed, Embase, Cochrane Library databases, and Chinese databases. No age, sex, and language restriction were set. The calculation formula was PPI $=100$ - [100*((prepulse - pulse amplitude) / pulse amplitude)]. The Newcastle-Ottawa Scale (NOS) was used to assess the quality of studies.

Results: Ten eligible papers were identified, of which five studies including a total of 141 euthymic patients and 132 healthy controls $(\mathrm{HC})$ were included in the meta-analysis. Compared with $\mathrm{HC}$, euthymic patients with BD had significantly lower PPI at the $60 \mathrm{~ms}$ interstimulus interval (ISI) between pulse and prepulse $\left(P=0.476, I^{2}=0.0 \%\right.$, $\mathrm{SMD}=-0.32,95 \% \mathrm{Cl}=-0.54--0.10$ ). Sensitivity analysis shows no significant change in the combined effect value after removing any single study. There was no publication bias using the Egger's test at $60 \mathrm{~ms}(P=0.606)$. The meta-analysis of PPI at the $60 \mathrm{~ms}$ ISI could have significant clinical heterogeneity in mood episode state, as well as lack of data on BD I or II subtypes.

Conclusions: Euthymic patients with BD show PPI deficits at the $60 \mathrm{~ms}$, suggesting a deficit in the early sensory gate underlying PPI. The PPI inhibition rate at a $60 \mathrm{~ms}$ interval is a stable index. More research is needed in the future to confirm this outcome, and to delve deeper into the mechanisms behind deficits.
\end{abstract}

Keywords: Bipolar disorder, Healthy controls, Prepulse inhibition, Systematic review, Meta-analysis

\section{Background}

In mammals, the startle reflex is caused by a sudden and intense sensory stimulation. It is an evolved defensive reflex activity that can interrupt and interfere with ongoing cognitive and behavioral activities [1-4]. A gating mechanism can effectively inhibit the startle reflex, to ensure normal brain function. The prepulse inhibition (PPI) is the application of a weak prepulse stimulus that does not trigger a startle reflex during the first $30-500$

\footnotetext{
* Correspondence: baj718@163.com

${ }^{1}$ The National Clinical Research Center for Mental Disorders \& Beijing Key Laboratory of Mental Disorders \& Beijing Institute for Brain Disorders Center of Schizophrenia, Beijing Anding Hospital, Capital Medical University, No.5 Ankang Lane, Dewai Avenue, Xicheng District, Beijing 100088, China

${ }^{2}$ Advanced Innovation Center for Human Brain Protection, Capital Medical University, Beijing 100069, China
}

ms before a strong stimulus. This interferes with and reduces the effects of the strong stimulus on the startle reflex [5]. PPI has good plasticity and has been widely used in various human and animal studies [6-10].

Previous studies have shown that PPI is regulated by the limbic-cortical-striatal-pallidal-thalamic (CSPT) neural circuit and the dopaminergic system [11, 12]. Further, it is found that injecting glutamatergic $\mathrm{N}$-methyl-d-aspartate (NMDA) into the hippocampus can disrupt PPI by affecting the expression of Gamma-Aminobutyric Acid (GABA) neurotransmitters and the neural circuit $[11,13]$. Braff et al. (1978) first found that patients diagnosed with schizophrenia had lower PPI than normal controls [14], and subsequent PPI research has focused on the schizophrenia spectrum population [15]. Moreover, PPI research with 
other mental disorders, including bipolar disorder (BD), obsessive-compulsive disorder, and autism spectrum disorders, has also been conducted [16-18], indicating that PPI abnormalities may be related to common psychopathological mechanisms of various disorders. PPI deficits have also been reported in first-degree relatives of patients with schizophrenia and BD, indicating that PPI may be a heritable phenotype [19, 20].

Although the neuromodulatory circuits of PPI are mainly at the brainstem level, many studies have confirmed that PPI is regulated by higher cognitive processes such as attention and emotion. Selective attention to prepulse stimulation can specifically enhance PPI in healthy subjects, while the enhancement effect in schizophrenia patients disappears due to attention deficit [21, 22]. Currently, some studies have shown that perceived spatial separation-induced PPI paradigm based on the priority effect can improve the individual recognition of prepulse sound and thus increase PPI [6]. Emotions play an important role in the selective attention and cognitive processes of people facing complex situations. For example, there can be higher PPI in response to pleasant or fearful pictures than to neutral pictures [23, 24]. Moreover, the CSPT circuit in BD patients may be impaired [25]. Deficits in this gating circuit could have adverse effects on cognitive information filtering, perhaps contributing to depressive thinking, manic thinking, and delusions.

Because of the complexity of $\mathrm{BD}$, previous studies have drawn inconsistent conclusions. Some studies have found that, compared with healthy controls $(\mathrm{HC})$, euthymic, or acute manic patients with $\mathrm{BD}$, and first-degree relatives had significantly lower PPI levels [16, 20, 26, 27]. However, other studies found that patients with $\mathrm{BD}$ in the euthymic period and pediatric BD did not show PPI deficits [28-30]. There has been no systematic review or meta-analysis of PPI in patients with BD to assess the overall magnitude of these effects. The present study comprehensively retrieved the literature on PPI in patients with $\mathrm{BD}$, then systematically reviewed the available data and conducted meta-analysis, comparing BD with $\mathrm{HC}$.

\section{Methods}

\section{Search strategy}

Two authors independently searched relevant articles from the start of the database to July 27, 2019 in PubMed, Embase, the Cochrane Library databases, and the Chinese databases (VIPS, CNKI, and Wan Fang). Searches used medical subject headings (MESH), text words, and Boolean calculations. Main search terms included: bipolar disorder; bipolar affective disorder; mania; manic-depressive; manic episode; hypomania; hypomanic episode; bipolar depression; bipolar I disorder; bipolar II disorder; bipolar type I; bipolar type II; psychosis; psychoses; psychotic; prepulse inhibition; PPI; startle reflex; startle reaction; sensorimotor gating; and sensory gating. We also searched for relevant references in known quantitative papers, including non-English papers. The search strategy has been provided as supplementary material (Additional file 1). This review performed according to the Preferred Reporting Items for Systematic reviews and Meta-Analyses (PRISMA) guidelines, which provides an evidence-based minimum set of items for reporting in systematic reviews and meta-analyses. PRISMA Checklist has been included as supporting information "PRISMA checklist.doc" (Additional file 2).

\section{Study selection criteria}

Two authors independently screened the literature by reading the titles, abstracts, and the full text. The criteria for inclusion in the meta-analysis were: (1) Presence of a HC group. When participants included people with schizophrenia, BD, and first-degree relatives, information on patients with BD was extracted. (2) The paper contained PPI data or histograms and corresponding general demographic information with a PPI formula of PPI $=100$ - [100*((prepulse - pulse amplitude)/pulse amplitude)]. (3) Presence of PPI data at $60 \mathrm{~ms}$ interstimulus interval (ISI). If the article contains both $60 \mathrm{~ms}$ and $120 \mathrm{~ms}$ PPI, $60 \mathrm{~ms}$ PPI data was extracted. (4) The quality of the research was evaluated by Newcastle-Ottawa Scale (NOS) [31]. This consists of nine items divided into three domains: selection of research subjects (four items); intergroup comparability (two items); and measurement of exposure factors (three items). The star system is used for semi-quantitative evaluation of research quality. The range of NOS is from zero to nine stars. Only papers with more than 4 stars were included in this study. Review papers, abstracts from conference proceedings and case reports were excluded. If the data were incomplete, the author was contacted by email to ask for information. If the author did not give a reply, we used the GetData software to extract the data in the paper. The two authors independently intercepted data to minimize errors in this study. Finally, we converted all standard error (SE) data into standard deviation (SD) form according to the formula $(\mathrm{SD}=\mathrm{SE} \times \sqrt{\mathrm{N}})$. Due to incomplete data, studies that cannot be converted are included in the qualitative description. When the two authors reached different conclusions about eligibility, the third author was consulted.

\section{Data analyses}

Statistical analysis was performed using the software STATA 11.0 (Stata Corporation, USA). The heterogeneity test was evaluated using the $\mathrm{I}^{2}$ value. When $\mathrm{I}^{2} \leq$ $50.0 \%$ and $P \geq 0.10$, it indicated that the included studies are homogeneous, and the model of fix effect was adopted. If $\mathrm{I}^{2}$ is greater than $50.0 \%$ and $P$ value is less 
than 0.10 , results was considered heterogeneous, then the random effects models and sensitivity analyses were used [32]. Because the included studies used different continuous measures as outcome measures, we calculated effect sizes (Standard Mean Difference, SMD) and the standard errors of the effect sizes by the Cohen method in the metan command [33]. Galbraith graphs were plotted to test heterogeneity. Additionally, the metaninf command was used to examine the effect of individual studies on the total combined effect after removing outliers. Through the metabias command, the Egger's test [34] was used to evaluate publication bias. The sample size, mean, SD, heterogeneity values $\left(\mathrm{I}^{2}, \mathrm{p}\right)$, SMD, and 95\% confidence interval $(\mathrm{CI})$ are shown in the forest map.

\section{Results}

\section{Included studies}

Figure 1 shows the article screening process: 815 unique articles were included in the initial screening, of which all but 16 were excluded after initial screening. Six more were excluded on further screening, leaving 10 papers included in qualitative synthesis, of which 5 were excluded from meta-analyses because of the absence of general demographic data, PPI data of $60 \mathrm{~ms}$ ISI and the maximum and minimum values required for data conversion. Therefore, five articles were included in final quantitative analysis for $60 \mathrm{~mm}$ ISI. The characteristics descriptions of all studies were displayed in Table 1.

\section{Meta analyses}

A total of 141 euthymic patients and $132 \mathrm{HC}$ were included in the meta-analysis of the $60 \mathrm{~ms}$ ISI. BD diagnoses in all 5 studies were according to Structured Clinical Interview for DSM Disorders-Fourth Edition (DSM-IV) criteria. The clinical characteristics and treatment of patients with $\mathrm{BD}$ are depicted in Table 2.

Furthermore, as shown in Table 2, in all five studies the PPI was calculated the same way and the mood state of patients with BD is euthymic. Therefore, we performed meta-analysis for PPI of $60 \mathrm{~ms}$ ISI. As can be seen in Fig. 2, there was an overall PPI difference between euthymic BD and $\mathrm{HC}$ at $60 \mathrm{~ms}$ ISI (SMD $=-0.32$, $95 \% \mathrm{CI}=-0.54--0.10)$.

\section{Quality assessments}

Using the NOS to assess the quality of the studies, all 5 papers gained 4 stars or more (Table 3 ).

\section{Heterogeneity and sensitivity analyses}

As shown in Fig. 2, the PPI of the $60 \mathrm{~ms}$ ISI had little heterogeneity $\left(P=0.476, \mathrm{I}^{2}=0.0 \%, \mathrm{SMD}=-0.32,95 \%\right.$ $\mathrm{CI}=-0.54--0.10)$. According to the heterogeneity analysis results for $60 \mathrm{~ms}$ PPI, all research points fall

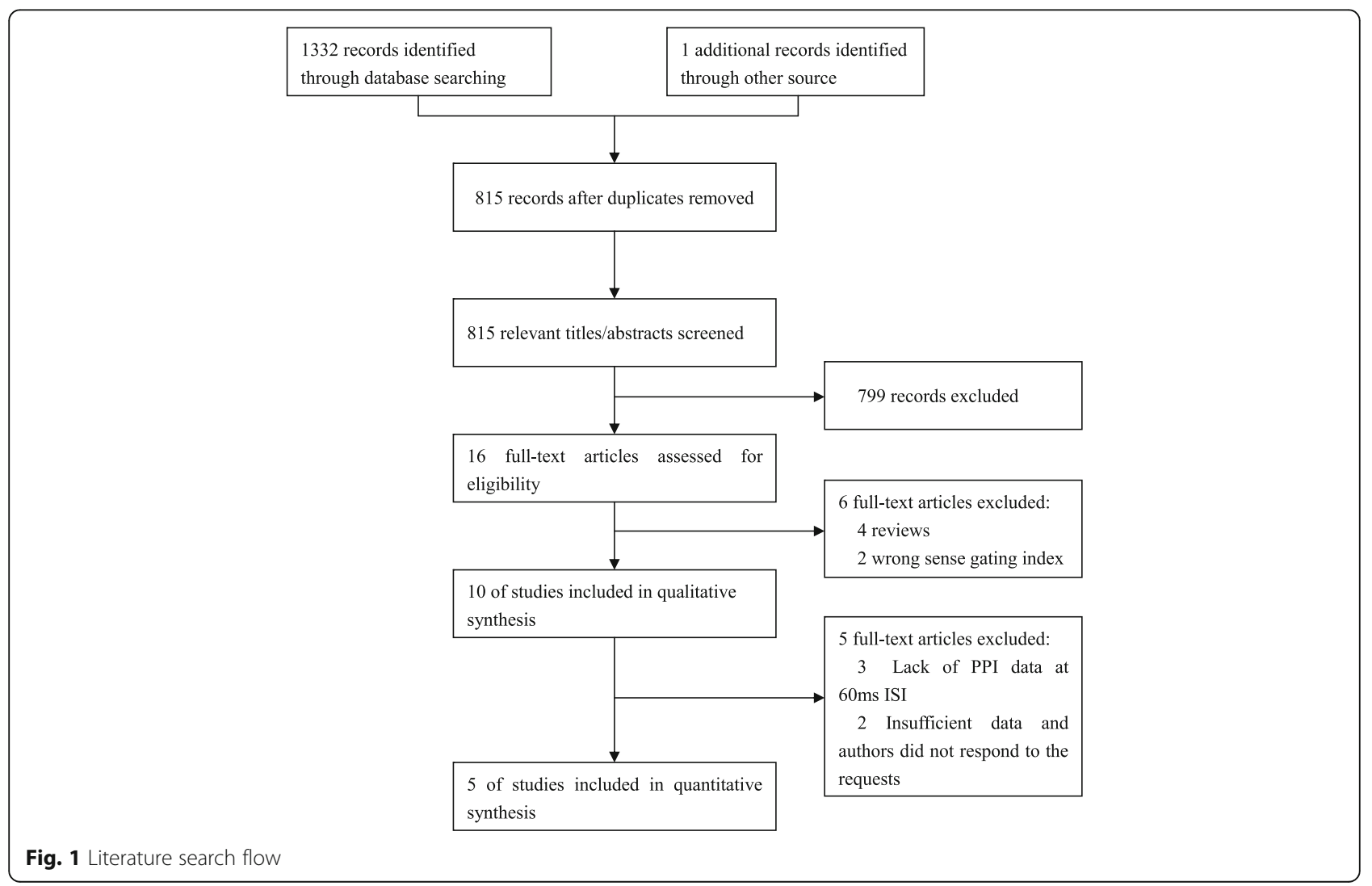




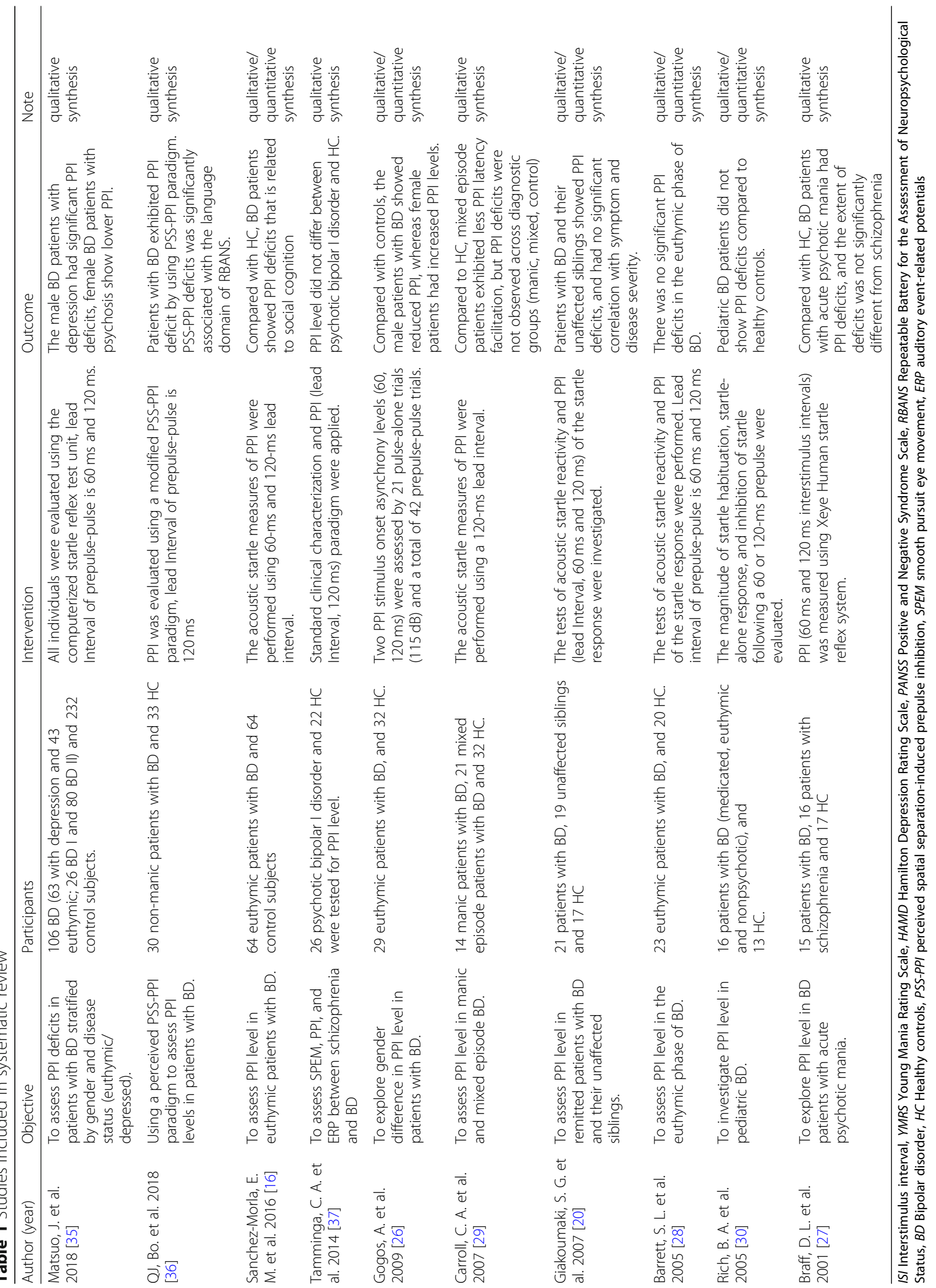




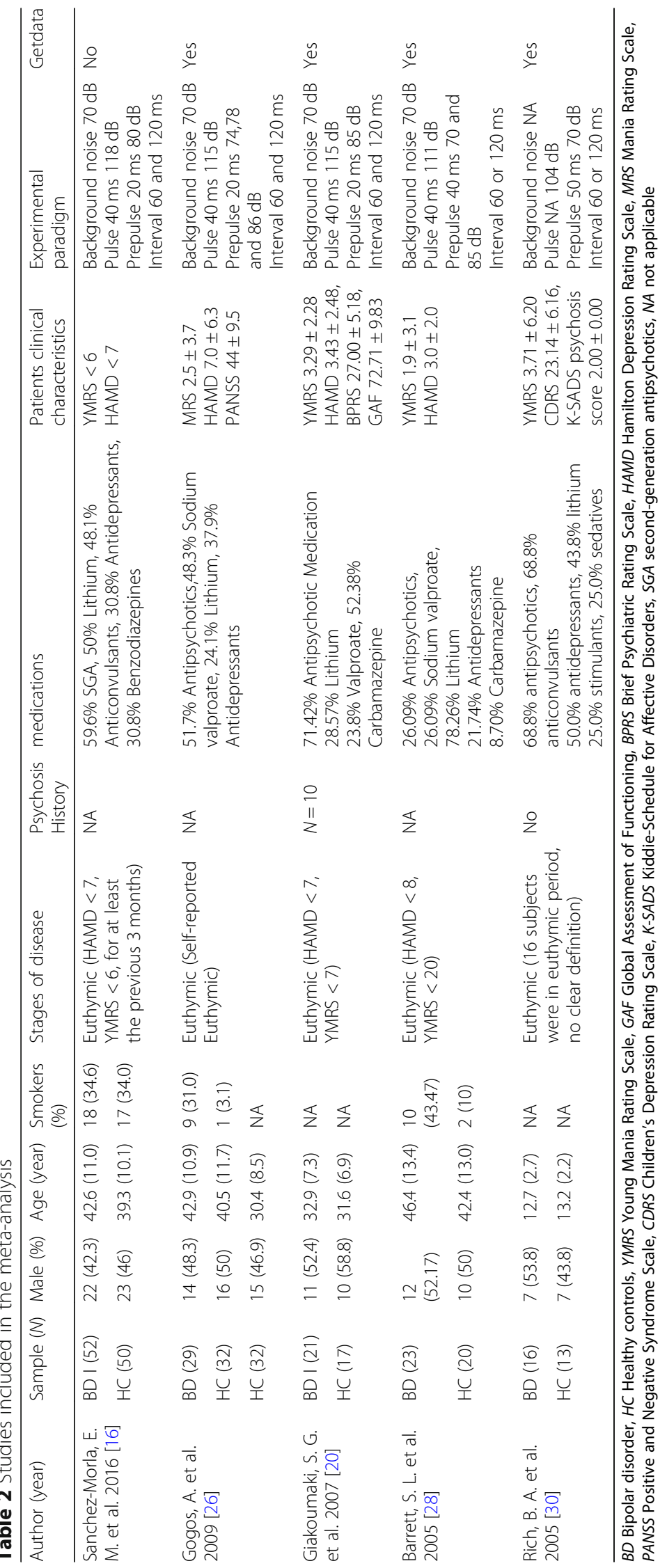




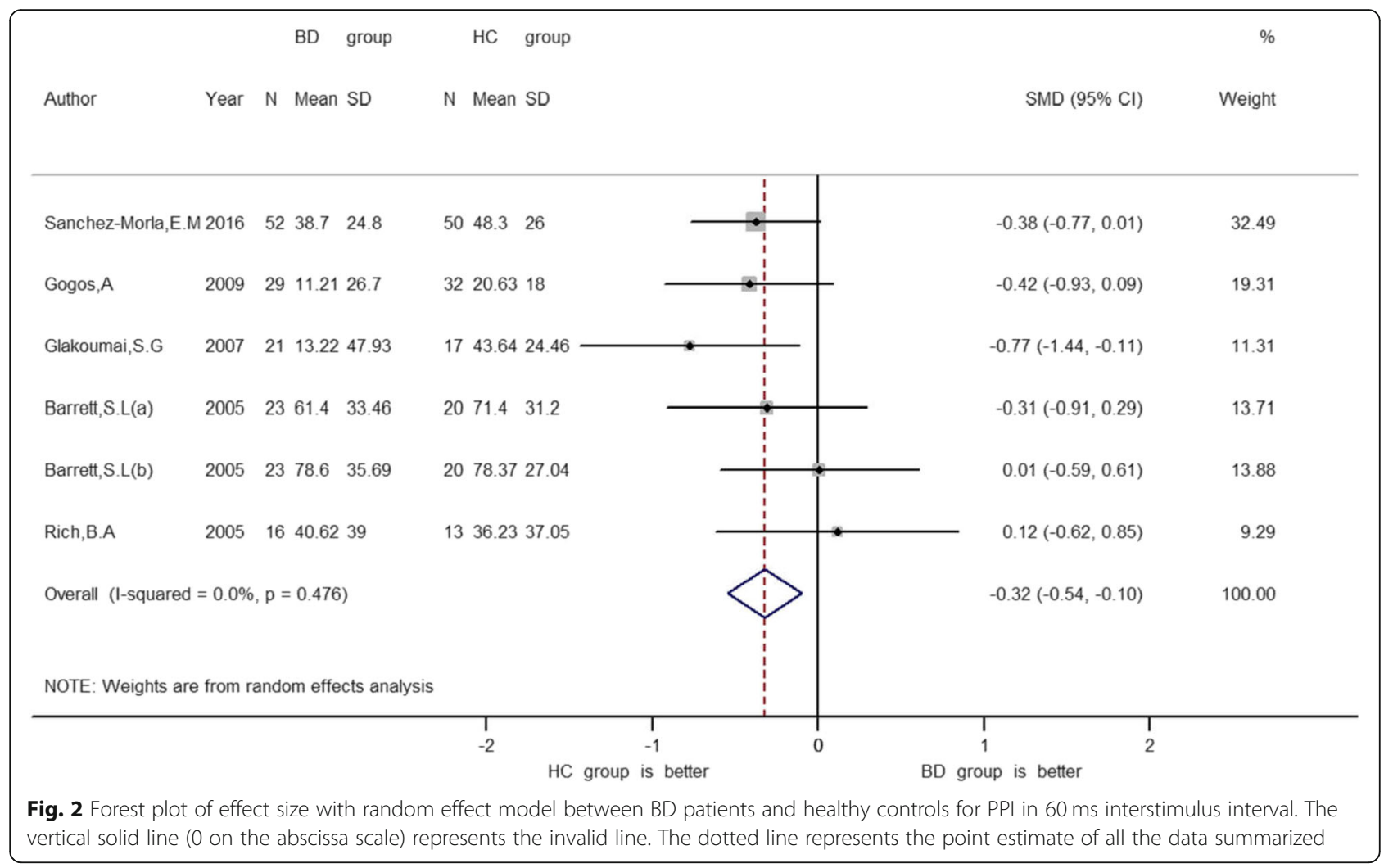

between two regression lines (Fig. 3). Sensitivity analysis shows no significant change in the combined effect value after removing this single study (Fig. 4). Due to lack of data on BD I or II subtypes, subgroup analyses of BD type cannot be obtained.

\section{Publication bias}

When using the Egger's test, there was no publication bias at $60 \mathrm{~ms}(P=0.606)$.

\section{Discussion}

To the best of our knowledge, this is the first systematic review and meta-analysis about PPI levels in patients with BD. The main finding of this study is that euthymic patients with $\mathrm{BD}$ had significant PPI deficits compared with $\mathrm{HC}$ when the ISI between pulse and prepulse was $60 \mathrm{~ms}$. In the PPI paradigm of human studies, the ISI generally range from between 30 and $240 \mathrm{~ms}$. It was found that maximum PPI occurs at $60-120 \mathrm{~ms}$ ISI in schizophrenia patients and normal subjects [14, 39, 40].

Table $\mathbf{3}$ The quality assessment by NOS scale

\begin{tabular}{|c|c|c|c|c|c|c|c|c|c|}
\hline & $\begin{array}{l}\text { The Case } \\
\text { Definition }\end{array}$ & $\begin{array}{l}\text { Representativeness } \\
\text { of the Cases }\end{array}$ & $\begin{array}{l}\text { Selection } \\
\text { of Controls }\end{array}$ & $\begin{array}{l}\text { Definition } \\
\text { of Controls }\end{array}$ & Comparability(a) & Comparability (b) & Exposure (1) & Exposure (2) & Exposure $(3)^{a}$ \\
\hline $\begin{array}{l}\text { Sanchez- } \\
\text { Morla, E. M. } \\
\text { et al. } 2016\end{array}$ & $*$ & $*$ & & $*$ & * & $*$ & $*$ & $*$ & \\
\hline $\begin{array}{l}\text { Gogos, A. } \\
\text { et al. } 2009\end{array}$ & $*$ & $*$ & $*$ & $*$ & $*$ & $*$ & $*$ & $*$ & \\
\hline $\begin{array}{l}\text { Giakoumaki, } \\
\text { S. G. et al. } \\
2007\end{array}$ & $*$ & $*$ & $*$ & $*$ & * & * & $*$ & * & \\
\hline $\begin{array}{l}\text { Barrett, S. L. } \\
\text { et al. } 2005\end{array}$ & $*$ & $*$ & * & * & $*$ & $*$ & $*$ & * & \\
\hline $\begin{array}{l}\text { Rich, B. A. } \\
\text { et al. } 2005\end{array}$ & $*$ & & & * & * & $*$ & * & $*$ & \\
\hline
\end{tabular}

NOS Newcastle-Ottawa Scale, ${ }^{a}$ When the chi-square test is greater than 0.05 , it indicates that the non-response rate between the two groups has no significant significanc e[38]

Comparability: confounding factors included age, sex, race, years of education and smoking status 


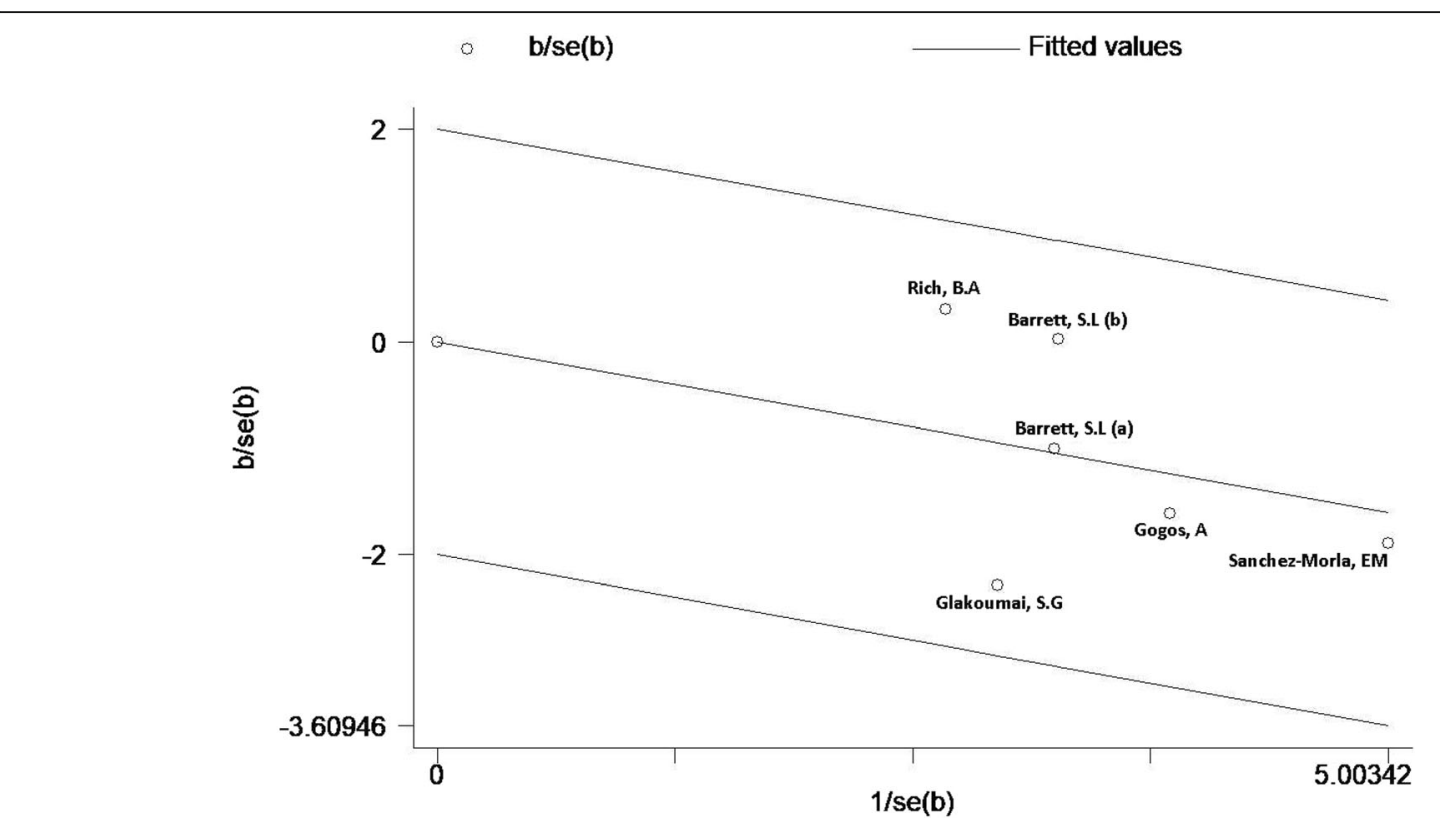

Fig. 3 The Galbraith plot for 60 ms PPI heterogeneity. There are three diagonal lines in the figure, the middle diagonal line represents combined value of the fixed effect, and the $95 \%$ confidence interval on both sides

Even if BD are treated with an mood stabilizers, atypical antipsychotics, or have a history of smoking, all of which can affect PPI, patients still have PPI deficits at $60 \mathrm{~ms}$ ISI. This suggests that BD is more associated with a deficit in the sensory gate at $60 \mathrm{~ms}$ ISI which is an insensitive interval for drugs that affect sensory gating [41-43].

The PPI at $120 \mathrm{~ms}$ ISI is regulated by attention and distribution in advanced cognitive function and is susceptible to drug effects [21]. A total of 10 studies explored PPI levels at $120 \mathrm{~ms}$ ISI in patients with BD and the conclusions are different. Four studies reported PPI defects of patients with BD and 4 studies showed no defects, other two studies explored gender differences in PPI and did not show differences between overall patients and HC. Currently, the studies include those with $\mathrm{BD}$ in euthymic, and mania/mixed states, as well as those with BD I or BD II, and it includes those with adults or children. The clinical heterogeneity of the 120 ms ISI in BD patients was more evident, so no metaanalysis was applied for 120 ISI. However, at present,

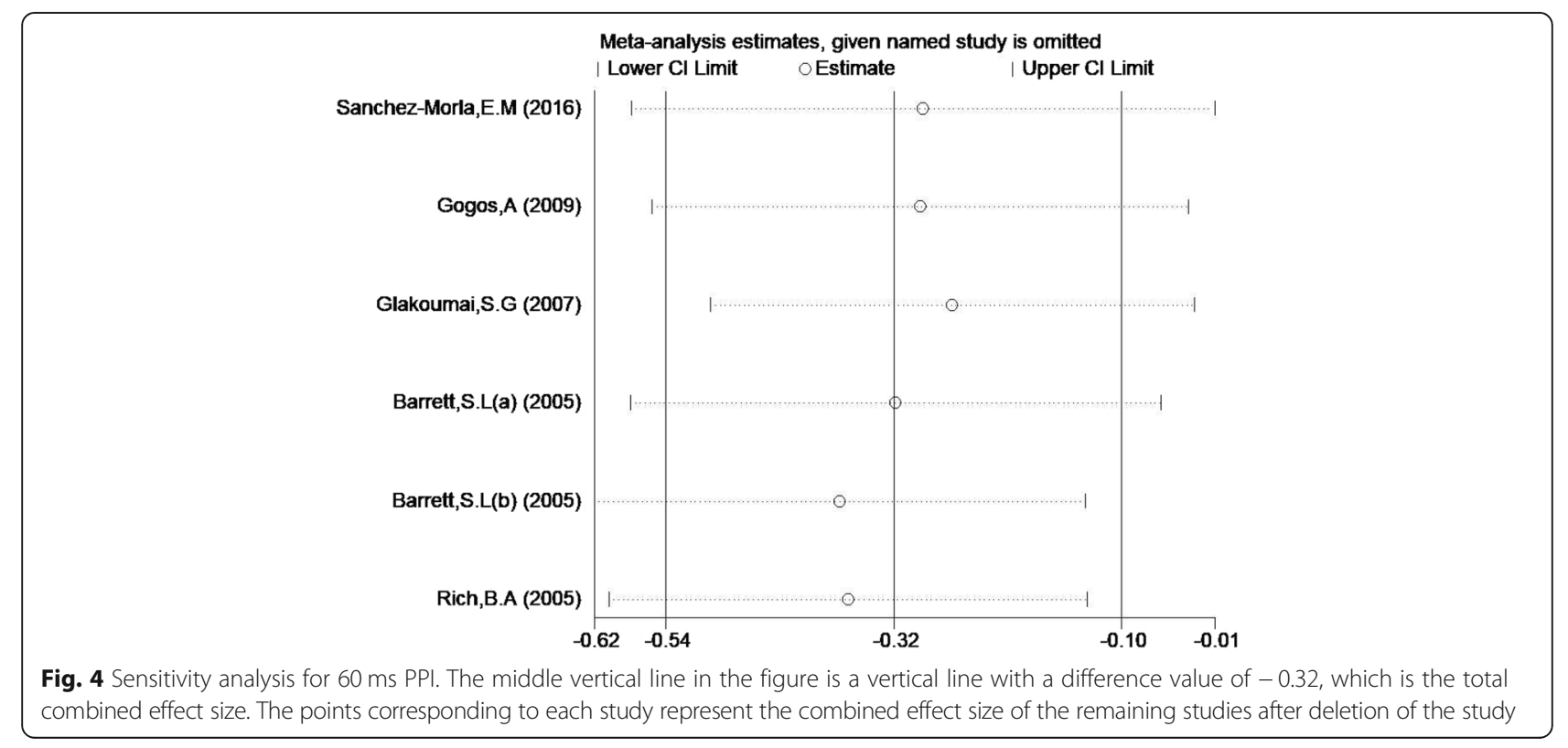


clinical heterogeneity is difficult to explain by analyzing data. Just for the heterogeneity depend on the current analyses, further study is needed with good design.

There are multiple definitions of the euthymic period in the literature reviewed. One study suggested that euthymia was defined as score below 7 on the Hamilton Depression Rating Score (HDRS) and below 6 on the Young Mania Rating Scale (YMRS) [16]. Another used criteria of less than 8 on Hamilton Depression Rating Scale (HAMD) and less than 20 on YMRS [28]. Another included euthymic (HAMD $<7$ and YMRS $<7$ ) patients with BD [20]. Yet another study relied on self-report [26]. However, despite inconsistent criteria, by these criteria all participants were considered clinically stable at time of testing. Euthymic patients with BD had PPI deficits at $60 \mathrm{~ms}$, suggesting a consistent association between $\mathrm{BD}$ and sensory gating deficit. This is consistent with previous studies, euthymic patients with BD still have functional deficits of sustained attention and find it difficult to ignore the irrelevant stimulus [44, 45]. At present, there is little research on PPI in the acute phase of $\mathrm{BD}$ and further research is needed. PPI deficits may be due to both trait and state characteristics.

Schizophrenia-related studies have shown that PPI deficits are strongly associated with positive symptoms $[9,46]$. A meta-analysis of the previous P50 showed that patients with BD have sensory gate deficits, which become more serious in when exhibiting psychotic symptoms [47]. One study found that psychotic patients with BD in the manic phase have significant PPI deficits [27]. Another study of manic patients without psychotic symptoms did not find this [29]. However, Sanchez-Morla et al. support the presence of PPI deficits in stable patients, which have no association with psychotic symptoms [16]. Since PPI is found in other non-psychotic disorders and is regulated by attention, patients with BD have sustained attention deficit in different stages of the disease, so it may be a trait characteristic of BD. Unfortunately, due to insufficient PPI data, we were unable to do the relevant subgroup analysis. The relationship with the psychotic symptoms of patients with $\mathrm{BD}$ remains to be further studied.

PPI deficits were first demonstrated in patients with schizophrenia and have been studied primarily in patients with schizophrenia spectrum disorders [14, 15]. This meta-analysis adds to the increasing evidence that patients with BD also have impaired PPI levels, suggesting that PPI deficits are not unique to schizophrenia. However, there is overlap of symptoms and genetic communalities between BD and schizophrenia [48]. It is possible that the sensory attentional deficit assessed by PPI involves some specific neurological mechanism implicated in both disorders. BD and schizophrenia in current diagnostic systems may be different manifestations of very similar underlying brain dysfunctions and clinical phenotypes of psychiatric disorder. This is therefore a promising direction for researching ways of understanding and classifying psychiatric disorders by their biological causes, rather than by their symptom clusters.

There are some limitations of this study. PPI is affected by several types of factors. Firstly, among the literatures included in the quantitative analysis, patients in three literatures were not described the type of BD (bipolar I or II), and all the patients in the other two researches were BD I. An effective subgroup analysis cannot be performed. Secondly, according to the HAMD score, Gogos 2009 included those who were depressed assessed by HAMD [26]. The group mean is in the mild depression range, with the SD indicating that there were quite a few participants who were likely mildly depressed, but self-reported euthymic. Thirdly, PPI is affected by many factors. A number of previous studies found that the second generation of antipsychotics can improve PPI, and that mood stabilizers such as, lithium and valproate, can increase PPI [49-51]. Previously in the study of BD, most patients were prescribed drugs and had multiple drug combinations, which cannot be easily converted to equivalent dosages. PPI levels are also affected by gender, age, smoking, and other factors. Most studies suggest that male PPI levels are significantly higher than female $[52,53]$. Kumari et al. suggested that the level of PPI in minors is significantly lower than in adult patients [54]. nicotine can also improve PPI levels [55]. These factors are hard to control in research and may be causes of heterogeneity. Furthermore, to carry out quantitative analysis, we use data interception software to capture data from pictures in previous literature, resulting in no deviation results between the data used and the original data.

\section{Conclusions}

In conclusion, the current systematic review and metaanalysis suggests that BD patients show PPI deficits in the $60 \mathrm{~ms}$ ISI. Further research on PPI in disorders other than schizophrenia is needed, including BD during the acute phase and psychotic state, using consistent criteria for defining euthymic, acute phases, and psychotic state. More research is needed in the future to confirm this outcome, and to delve deeper into the mechanisms behind deficits.

\section{Supplementary information}

Supplementary information accompanies this paper at https://doi.org/10. 1186/s12888-019-2271-8.

Additional file 1: The search strategy. (DOCX $14 \mathrm{~kb}$ )

Additional file 2: PRISMA Checklist. (DOC 64 kb)

\section{Abbreviations}

BD: Bipolar Disorder; CSPT: Limbic-cortical-striatal-pallidal-thalamic; DSMIV. Structured Clinical Interview for DSM Disorders-Fourth Edition; GABA: Gamma-Aminobutyric Acid; HC: Healthy Controls; HDRS, 
HAMD: Hamilton Depression Rating Scale; ISI: Interstimulus Interval; MESH: Medical Subject Headings; NMDA: N-methyl-d-aspartate; NOS: Newcastle-Ottawa Scale; PPI: Prepulse Inhibition; PRISMA: Preferred Reporting Items for Systematic reviews and Meta-Analyses; YMRS: Young Mania Rating Scale

\section{Acknowledgments}

None.

\section{Authors' contributions}

Conceptualization: QB, ZM, Methodology: QB, ZM, Software: ZM, QB, WL, Validation: ZM, ZW, Formal analysis: QB, ZM, ZW, Investigation: QB, ZM, ZW, Resources: $Q B, Z M, Z W$, Data curation: $Q B, Z M, W L$, Writing (original draft preparation): $\mathrm{QB}, \mathrm{ZM}$, Writing (review and editing): $\mathrm{CW}, \mathrm{QB}$, Project administration: $\mathrm{CW}, \mathrm{XM}, \mathrm{QB}$, Funding acquisition: QB. All authors have read and approved the manuscript.

\section{Author's information}

All researchers in the study were trained regarding the protocol and Good Clinical Practice guidelines.

1 The National Clinical Research Center for Mental Disorders \& Beijing Key Laboratory of Mental Disorders \& Beijing Institute for Brain Disorders Center of Schizophrenia, Beijing Anding Hospital, Capital Medical University, Beijing 100,088, China.

2 Advanced Innovation Center for Human Brain Protection, Capital Medical University, Beijing, 100,069, China.

\section{Funding}

The design of the article was inspired by the Beijing Municipal Administration of Hospital Youth Program (QML20171901) project. The cost of authors participating in the meta-analysis methodology training is funded by the Beijing Municipal Administration of Hospital Youth Program (QML20171901), and Beijing Municipal Administration of Hospitals Clinical Medicine Development of Special Funding Support (ZYLX201807) project, and writing training is supported by National Natural Science Foundation of China (81901355) and Beijing Municipal Natural Science Foundation (7192081). No investigator benefited from participating in the study.

\section{Availability of data and materials}

Data are available from the first and the corresponding authors.

\section{Ethics approval and consent to participate}

The study protocols were approved by the clinical research ethics committees of Beijing Anding Hospital, Capital Medical University.

\section{Consent for publication}

Not applicable.

\section{Competing interests}

The authors declare that they have no competing interests.

Received: 8 December 2018 Accepted: 3 September 2019 Published online: 11 September 2019

\section{References}

1. Hunt, Alvin W: The startle pattern: Farrar \& Rinehart, Inc.; 1939

2. Hoffman HS, Jr WO. Performance disruption by startle-eliciting acoustic stimuli. Psychon Sci. 1971;24(5):233-5.

3. Foss JA, Ison JR Jr, TJ WS. The acoustic startle response and disruption of aiming: II. Modulation by forewarning and preliminary stimuli. Hum Factors. 1989;31(3):319-33.

4. Foss JA, Ison JR, Wansack $S$. The acoustic startle response and disruption of aiming: I. effect of stimulus repetition, intensity, and intensity changes. Hum Factors. 1989;31(3):307-18.

5. Graham FK. Presidential Address, 1974. The more or less startling effects of weak prestimulation. Psychophysiology. 1975;12(3):238.

6. Li L, Du Y, Li N, Wu X, Wu Y. Top-down modulation of prepulse inhibition of the startle reflex in humans and rats. Neurosci Biobehav Rev. 2009;33(8):1157-67.

7. Zhu F, Zhang L, Ding YQ, Zhao J, Zheng Y. Neonatal intrahippocampa injection of lipopolysaccharide induces deficits in social behavior and prepulse inhibition and microglial activation in rats: implication for a new schizophrenia animal model. Brain Behav Immun. 2014;38:166-74.

8. Weike Al, Bauer U, Hamm AO. Effective neuroleptic medication removes prepulse inhibition deficits in schizophrenia patients. Biol Psychiatry. 2000; 47(1):61-70.

9. Wang ZR, Tan YL, Yang FD, Zhang WF, Zou YZ, Tan SP, Song CS, Li YL, Zhang WH, Zhou DF. Impaired prepulse inhibition of acoustic startle in Chinese patients with first-episode, medication-naive schizophrenia. Chin Med J. 2013;126(3):526-31.

10. Kumari V, Sharma T. Effects of typical and atypical antipsychotics on prepulse inhibition in schizophrenia: a critical evaluation of current evidence and directions for future research. Psychopharmacology. 2002;162(2):97-101.

11. Koch M, Schnitzler HU. The acoustic startle response in rats--circuits mediating evocation, inhibition and potentiation. Behav Brain Res. 1997; 89(1-2):35-49.

12. Medan V, Preuss T. Dopaminergic-induced changes in Mauthner cell excitability disrupt prepulse inhibition in the startle circuit of goldfish. J Neurophysiol. 2011;106(6):3195-204.

13. Wang J, Li G, Xu Y, Zhang WN. Hyperactivity and disruption of prepulse inhibition induced by NMDA infusion of the rat ventral hippocampus: comparison of uni- and bilateral stimulation. Neurosci Lett. 2015:594:150-4.

14. Braff D, Stone C, Callaway E, Geyer M, Glick I, Bali L. Prestimulus effects on human startle reflex in normals and schizophrenics. Psychophysiology. 1978; 15(4):339-43.

15. Swerdlow NR, Braff DL, Geyer MA. Sensorimotor gating of the startle reflex: what we said 25 years ago, what has happened since then, and what comes next. J Psychopharmacol (Oxford, England). 2016;30(11):1072-81.

16. Sanchez-Morla EM, Mateo J, Aparicio A, Garcia-Jimenez MA, Jimenez E, Santos JL. Prepulse inhibition in euthymic bipolar disorder patients in comparison with control subjects. Acta Psychiatr Scand. 2016;134(4):350-9.

17. Swerdlow NR, Benbow CH, Zisook S, Geyer MA, Braff DL. A preliminary assessment of sensorimotor gating in patients with obsessive compulsive disorder. Biol Psychiatry. 1993;33(4):298-301.

18. Cheng CH, Chan PS, Hsu SC, Liu CY. Meta-analysis of sensorimotor gating in patients with autism spectrum disorders. Psychiatry Res. 2017;262:413-9.

19. Cadenhead KS, Swerdlow NR, Shafer KM, Diaz M, Braff DL Modulation of the startle response and startle laterality in relatives of schizophrenic patients and in subjects with schizotypal personality disorder: evidence of inhibitory deficits. Am J Psychiatry. 2000;157(10):1660-8.

20. Giakoumaki SG, Roussos P, Rogdaki M, Karli C, Bitsios P, Frangou S. Evidence of disrupted prepulse inhibition in unaffected siblings of bipolar disorder patients. Biol Psychiatry. 2007;62(12):1418-22.

21. Dawson ME, Hazlett EA, Filion DL, Nuechterlein KH, Schell AM. Attention and schizophrenia: impaired modulation of the startle reflex. J Abnorm Psychol. 1993;102(4):633-41.

22. Dawson ME, Schell AM, Hazlett EA, Nuechterlein KH, Filion DL. On the clinical and cognitive meaning of impaired sensorimotor gating in schizophrenia. Psychiatry Res. 2000;96(3):187-97.

23. Bradley MM, Cuthbert BN, Lang PJ. Pictures as prepulse: attention and emotion in startle modification. Psychophysiology. 1993;30(5):541-5

24. Mishra MV, Ray SB, Srinivasan N. Effect of emotions on temporal attention. Prog Brain Res. 2017;236:287-309.

25. Sheline YI. Neuroimaging studies of mood disorder effects on the brain. Biol Psychiatry. 2003;54(3):338-52.

26. Gogos A, van den Buuse M, Rossell S. Gender differences in prepulse inhibition (PPI) in bipolar disorder: men have reduced PPI, women have increased PPI. Int J Neuropsychopharmacol. 2009;12(9):1249-59.

27. Perry W, Minassian A, Feifel D, Braff DL. Sensorimotor gating deficits in bipolar disorder patients with acute psychotic mania. Biol Psychiatry. 2001. 50(6):418-24.

28. Barrett SL, Kelly C, Watson DR, Bell R, King DJ. Normal levels of prepulse inhibition in the euthymic phase of bipolar disorder. Psychol Med. 2005; 35(12):1737-46.

29. Hill A, Frenzel L, Meyhofer I, Wagner M, Backhaus J, Kumari V, Carroll CA, Vohs JL, O'Donnell BF, Shekhar A, et al. Sensorimotor gating in manic and mixed episode bipolar disorder. J Neurosci. 2007;9(3):221-9.

30. Rich BA, Vinton D, Grillon C, Bhangoo RK, Leibenluft E. An investigation of prepulse inhibition in pediatric bipolar disorder. Bipolar Disord. 2005:7(2): 198-203.

31. Wells GA, Shea BJ, O'Connell D, Peterson J, Welch V, Losos M, Tugwell P: The Newcastle-Ottawa Scale (NOS) for Assessing the Quality of Non- 
Randomized Studies in Meta-Analysis. Appl Eng Agric 2012, 18(6):págs. 727-734.

32. Higgins JP, Thompson SG, Deeks JJ, Altman DG. Measuring inconsistency in meta-analyses. BMJ. 2003;327(7414):557.

33. DerSimonian R, Laird N. Meta-analysis in clinical trials. Control Clin Trials. 1986;7(3):177-88.

34. Egger M, Smith GD, Schneider M, Minder C. Bias in meta-analysis detected by a simple, graphical test. Bmj. 1997;315(7109):629-34.

35. Matsuo J, Ota M, Hidese S, Teraishi T, Hori H, Ishida I, Hiraishi M, Kunugi H: Sensorimotor gating in depressed and euthymic patients with bipolar disorder: Analysis on prepulse inhibition of acoustic startle response stratified by gender and state. Front Psychiatry. 2018, 9(APR) 123.

36. Bo Q, Mao Z, Tian Q, Wen Y, Dong F, Li X, Wang Z, Ma X, Wang C. Deficits of perceived spatial separation-induced prepulse inhibition in patients with bipolar disorder compared to healthy controls. J Affect Disord. 2018;240:63-71.

37. Ivleva El, Moates AF, Hamm JP, Bernstein IH, O'Neill HB, Cole D, Clementz BA, Thaker GK, Tamminga CA. Smooth pursuit eye movement, prepulse inhibition, and auditory paired stimuli processing endophenotypes across the schizophrenia-bipolar disorder psychosis dimension. Schizophr Bull. 2014;40(3):642-52.

38. Sanchez-Gonzalez A, Oliveras I, Rio-Alamos C, Piludu MA, Gerboles C, Tapias-Espinosa C, Tobena A, Aznar S, Fernandez-Teruel A. Dissociation between schizophrenia-relevant behavioral profiles and volumetric brain measures after long-lasting social isolation in Roman rats. Neurosci Res. 2019.

39. Ison JR, Pinckney LA. Reflex inhibition in humans: sensitivity to brief silent periods in white noise. Percept Psychophys. 1983;34(1):84-8.

40. Braff DL, Geyer MA, Swerdlow NR. Human studies of prepulse inhibition of startle: normal subjects, patient groups, and pharmacological studies. Psychopharmacology. 2001;156(2-3):234-58.

41. Bitsios P, Giakoumaki SG, Theou K, Frangou S. Increased prepulse inhibition of the acoustic startle response is associated with better strategy formation and execution times in healthy males. Neuropsychologia. 2006;44(12):2494-9.

42. Rabin RA, Sacco KA, George TP. Correlation of prepulse inhibition and Wisconsin card sorting test in schizophrenia and controls: effects of smoking status. Schizophr Res. 2009;114(1-3):91-7.

43. Laurenson C, Gorwood P, Orsat M, Lhuillier JP, Le Gall D, Richard-Devantoy S. Cognitive control and schizophrenia: the greatest reliability of the Stroop task. Psychiatry Res. 2015;227(1):10-6.

44. Clark L, Goodwin GM. State- and trait-related deficits in sustained attention in bipolar disorder. Eur Arch Psychiatry Clin Neurosci. 2004;254(2):61-8.

45. Bora E, Vahip S, Akdeniz F. Sustained attention deficits in manic and euthymic patients with bipolar disorder. Prog Neuro-Psychopharmacol Biol Psychiatry. 2006;30(6):1097-102.

46. Braff DL, Swerdlow NR, Geyer MA. Symptom correlates of prepulse inhibition deficits in male schizophrenic patients. Am J Psychiatry. 1999; 156(4):596-602.

47. Cheng CH, Chan PY, Liu CY, Hsu SC. Auditory sensory gating in patients with bipolar disorders: a meta-analysis. J Affect Disord. 2016;203:199-203.

48. Lee SH, Ripke S, Neale BM, Faraone SV, Purcell SM, Perlis RH, Mowry BJ, Thapar A, Goddard ME, Witte JS, et al. Genetic relationship between five psychiatric disorders estimated from genome-wide SNPs. Nat Genet. 2013; 45(9):984-94.

49. Lipina TV, Haque FN, McGirr A, Boutros PC, Berger T, Mak TW, Roder JC, Wong AH. Prophylactic valproic acid treatment prevents schizophrenia-related behaviour in Disc1-L100P mutant mice. PLoS One. 2012;7(12):e51562.

50. Flood DG, Choinski M, Marino MJ, Gasior M. Mood stabilizers increase prepulse inhibition in DBA/2NCrl mice. Psychopharmacology. 2009;205(3):369-77.

51. Csomor PA, Preller KH, Geyer MA, Studerus E, Huber T, Vollenweider FX. Influence of aripiprazole, risperidone, and Amisulpride on sensory and sensorimotor gating in healthy 'low and high Gating'Humans and relation to psychometry. Neuropsychopharmacology. 2014;39(10):2485.

52. Swerdlow NR, Auerbach P, Monroe SM, Hartston H, Geyer MA, Braff DL. Men are more inhibited than women by weak prepulses. Biol Psychiatry. 1993; 34(4):253-60.

53. Rahman Q, Kumari V, Wilson GD. Sexual orientation-related differences in prepulse inhibition of the human startle response. Behav Neurosci. 2003; 117(5):1096.

54. Kumari V, Soni W, Mathew VM, Sharma T. Prepulse inhibition of the startle response in men with schizophrenia: effects of age of onset of illness, symptoms, and medication. Arch Gen Psychiatry. 2000;57(6):609-14.
55. Hong LE, Wonodi I, Lewis J, Thaker GK. Nicotine effect on prepulse inhibition and prepulse facilitation in schizophrenia patients. Neuropsychopharmacology. 2008;33(9):2167.

\section{Publisher's Note}

Springer Nature remains neutral with regard to jurisdictional claims in published maps and institutional affiliations.
Ready to submit your research? Choose BMC and benefit from:

- fast, convenient online submission

- thorough peer review by experienced researchers in your field

- rapid publication on acceptance

- support for research data, including large and complex data types

- gold Open Access which fosters wider collaboration and increased citations

- maximum visibility for your research: over $100 \mathrm{M}$ website views per year

At BMC, research is always in progress.

Learn more biomedcentral.com/submissions 